\title{
Correlation of Levels of Oncostatin M Cytokine in Crevicular Fluid and Serum in Periodontal Disease
}

\author{
ManojKumar Thorat*, Pradeep AR, Garima Garg \\ Department of Periodontics, Government Dental College and Research Institute, Karnataka, India
}

\begin{abstract}
Aim The aim of this study was to measure the level of Oncostatin M (OSM) a gp130 cytokine in the gingival crevicular fluid (GCF) and serum of chronic periodontitis patients and to find any correlation between them before and after periodontal therapy (scaling and root planing, SRP).

Methodology 60 subjects (age 25-50 years) were enrolled into three groups ( $n=20$ per group), group I (healthy), group II (gingivitis) and group III (chronic periodontitis). Group III subjects were followed for 6-8 weeks after the initial periodontal therapy (SRP) as the group IV (after periodontal therapy). Clinical parameters were assessed as gingival index (GI), probing depth (PD), clinical attachment level (CAL), and radiographic evidence of bone loss. GCF and serum levels of OSM were measured by using Enzyme Linked Immunosorbent Assay (ELISA).
\end{abstract}

Results It was found that mean OSM levels had been elevated in both the GCF and serum of chronic periodontitis subjects $\left(726.65 \pm 283.56\right.$ and $65.59 \pm 12.37 \mathrm{pg} \cdot \mathrm{mL}^{-1}$, respectively) and these levels were decreased proportionally after the periodontal therapy $(95.50 \pm 38.85$ and $39.98 \pm$ $16.69 \mathrm{pg} \cdot \mathrm{mL}^{-1}$ respectively). However, OSM was detected in GCF of healthy subjects $\left(66.15 \pm 28.10 \mathrm{pg} \cdot \mathrm{mL}^{-1}\right)$ and gingivitissuffering subjects $\left(128.33 \pm 22.96 \mathrm{pg} \cdot \mathrm{mL}^{-1}\right)$ and was found as below the detectable limit $\left(\approx 0.0 \mathrm{pg} \cdot \mathrm{mL}^{-1}\right)$ in the serum of same subjects. Significant correlation has been found between clinical parameters and GCF-serum levels of OSM. Conclusion Increased OSM level both in the GCF and serum, and the decreased levels after initial periodontal therapy (SRP) may suggest a use as an inflammatory biomarker in the periodontal disease.

Keywords cytokine, Oncostatin M, chronic periodontitis, gingivitis, scaling and root planning

Received Mar. 15, 2010; Revision accepted Aug. 27, 2010

\section{Introduction}

Periodontitis is an inflammatory disease fundamentally initiated by a chronic bacterial infection (Listgarten, 1986; Jotwani and Cutler, 1998). Current data suggest that a small group of predominantly gram-negative anaerobic or microaerophilic bacteria within the biofilm (dental plaque) are often associated with disease initiation and progression. The microbial challenge consisting of antigens, lipopolysaccharides, and other virulent factors stimulates host responses. Host reactions to these infecting agents result in the release of inflammatory mediators (by cells like neutrophils, monocyte/ macrophages, T cells, mast cells, endothelial cells, fibroblasts) including proinflammatory cytokines (IL-1, IL-6, TNF- $\alpha$ ) and prostaglandins (PGE2), which can promote extracellular matrix destruction (by matrix metalloproteinase; MMPs) in the periodontium and stimulate bone resorption (BirkedalHansen, 1993). Although these immune and inflammatory host reactions are essential for host defense against bacterial inflammation, excessive and prolonged reaction is harmful for the functional periodontal tissue.

The analysis of cytokine production levels has been also used as a tool for studying the local host response to a bacterial challenge. In particular, a large number of cytokines present in the gingival crevicular fluid (GCF) have been proposed as 
potentially useful diagnostic or prognostic markers of periodontal destruction (Genco, 1998; Kamma et al., 2009). Various, proinflammatory cytokines like IL-1, IL-8, IL-6, TNF- $\alpha$; as well as anti-inflammatory cytokines like IL-4 and IL-10, were most-commonly studied in the GCF, gingival tissue and serum of the healthy, gingivitis, and chronic periodontitis patients (Stashenko et al., 1991; Shapira et al., 1992; Fujihashi et al., 1993; Okada and Murakami, 1998; Yun et al., 2007; Blach et al., 2009; Bokhari et al., 2009). Also, studies showed the pronounced effect of periodontal therapy (initial periodontal or surgical therapy) on levels of these cytokines (Mealey, 1999; Talbert et al., 2006; Dağ et al., 2009). This increased cytokines level in periodontitis may also exaggerate the systemic conditions, like atherosclerosis, diabetes, rheumatoid arthritis, preterm birth, and respiratory conditions. Recently, it has been considered as a risk factor for aforementioned conditions (Page and Beck, 1997). It is evident that the major sources of RANKL that mediate alveolar bone loss in periodontitis in vivo are lymphocytes (i.e. T-cells and B-cells) and certain types of monocyte/macrophage subsets. This indicates that the RANKL/RANK/osteoprotegerin axis is the key pathway and master-switch controlling osteoclastogenesis in the periodontium. Further evidence from recent studies links the RANKL/RANK/osteoprotegerin system to human periodontal disease, and have elegantly demonstrated that the RANKL and osteoprotegerin levels in gingival crevicular fluid and infected periodontal tissues are reciprocally and differentially-regulated in subjects with different forms of periodontitis (high RANKL : osteoprotegerin ratio), but not so in disease-free healthy and gingivitis subjects (low RANKL : osteoprotegerin ratio) (Vernal et al., 2004; Lu et al., 2006; Bostanci et al., 2007). This suggests their important and critical role in periodontal pathogenesis and their potential usefulness to periodontal diagnosis.

Oncostatin M (OSM) is a gp130 multifunctional cytokine that belongs to the IL- 6 subfamily and produced mainly by activated $\mathrm{T}$ cells, neutrophils, monocytes, and macrophages (Tanaka and Miyajima, 2003). More recently, it has also been demonstrated that OSM is produced by dendritic cells (Suda et al., 2002). OSM has been found to fulfill Koch's postulates as an inflammatory mediator (Modur et al., 1997). OSM may act alone or synergistically with IL-6/TNF- $\alpha$ stimulating the production of IL-6, to up-regulate the production of MMPs or augment IL-6 production which may cause connective tissue and bone destruction (Brown et al., 1991; Manicourt et al., 2000). Lin et al. studied the increased amount of OSM level in GCF and its positive correlation with IL-6 in the chronic periodontitis patients (Lin et al., 2005). Sakai et al. detected several cytokines in GCF using a cytokine antibody array system, including both inflammatory cytokines and various growth factors in periodontal healthy and chronic periodontitis subjects and found significant differences between healthy and diseased subjects' cytokine levels including OSM (Sakai et al., 2006).

Again, the increased OSM expression and its role in the pathogenesis of various systemic diseases such as atherosclerosis (Modur et al., 1997), rheumatoid arthritis (Hui et al., 1997), multiple myeloma (Halin et al., 2000), and wound biology (Goren et al., 2006) have been evaluated. However, it has also been recognized that OSM exhibits unique activities that are not shared with the leukemia inhibitory factor (LIF) and accumulating evidence indicates that OSM is a unique cytokine that plays an important role for various biological systems such as inflammatory response, hematopoiesis, tissue remodeling, and development (Bruce et al., 1992).

Currently, no study has reported the OSM levels in GCF and serum in various stages of periodontal disease including periodontal health, gingivitis and chronic periodontitis and has not correlated it before and after periodontal therapy. Thus, in view of the aforementioned findings, this study was carried out to estimate the GCF and serum OSM levels in subjects with the clinically healthy, gingivitis and chronic periodontitis subjects and subsequently, after nonsurgical periodontal therapy, i.e. scaling and root planning (SRP), in subjects with periodontitis.

\section{Materials and Methods}

Sixty subjects $(n=60 ; 30$ men and 30 women; age range: 25 to 50 years) attending the outpatient clinic of the Department of Periodontics, Government Dental College and Research Institute, Ban- 
galore, India. Patients were excluded from the study if they had aggressive periodontitis based on primary and secondary criteria suggested by Lang et al. (1999), diabetes, cardiovascular diseases, multiple myeloma, rheumatoid arthritis, smoking habits, tumors, or any other systemic disease or conditions (like pregnancy, menopause, having body mass index $>25 \mathrm{~kg} \cdot \mathrm{m}^{-2}$ ) that could alter the course of periodontal disease; were taking medication antibiotics, anti-inflammatory drugs, or received periodontal therapy in the preceding six months. Written informed consent was obtained from those who agreed to participate voluntarily, and ethical clearance was obtained from the institution's ethical committee (ACA/SYN/GDC-B/PG/20072008 dated on 3/4/2008). Each subject underwent a full-mouth periodontal probing and charting, and intraoral periapical radiographs were taken to assess the bone loss (dichotomously: presence or absence) to differentiate patients with chronic periodontitis from other groups.

Subjects were initially categorized into three groups based on the gingival index (GI) (Loe and Silness, 1963), probing depth (PD), clinical attachment level (CAL), and radiographic evidence of bone loss for screening purposes. Group I (healthy, $n=20,28.75 \pm 3.78$ years) subjects with clinicallyhealthy periodontium, $\mathrm{GI}=0$ (absence of clinical inflammation) and $\mathrm{PD}<3 \mathrm{~mm}$, and $\mathrm{CAL}=0$, showed no evidence of bone loss based on the radiographs. Group II (gingivitis, $n=20,28.5 \pm 4.01$ years) subjects who showed clinical signs of gingival inflammation, $\mathrm{GI}>1, \mathrm{PD} \leq 3 \mathrm{~mm}$, had no CAL or radiographic bone loss. Group III (chronic generalized periodontitis $\geq 30$ diseased sites, $n=20,30.6 \pm$ 6.24 years) consisted of 20 subjects who had signs of clinical inflammation, $\mathrm{GI}>1, \mathrm{PD} \geq 5 \mathrm{~mm}$, and $\mathrm{CAL} \geq 2 \mathrm{~mm}$, with radiographic evidence of bone loss. Patients with chronic periodontitis (group III) were treated with a non-surgical approach i.e. SRP; GCF and serum samples were collected from the same sites six to eight weeks after the treatment and considered as group IV (the after-treatment group).

All clinical measurements, at baseline and after treatment, were performed by a single examiner. PD and CAL were measured using a William's graduated periodontal probe. The patients were instructed for self-performed plaque-control mea- sures, like twice tooth brushing and dental floss etc.

\section{Site selection and GCF sample collection}

In the gingivitis and periodontitis groups, only one site per subject was selected as a sampling site; whereas in the healthy group, multiple sites (three to five sites per subject) with an absence of inflammation were sampled to ensure the collection of an adequate amount of GCF. In patients with gingivitis, the site with the greatest clinical signs of inflammation (i.e., redness, bleeding on probing, and edema), in the absence of CAL was selected. In chronic periodontitis, sites with $\mathrm{CAL} \geq 2 \mathrm{~mm}$ were identified using a Williams graduated periodontal probe, and the site showing the greatest $\mathrm{CAL}$ and signs of inflammation, along with radiographic bone loss, was selected for sampling; the same test site was selected after treatment for sampling. On the subsequent day, the sample collection site was well-isolated and without touching the marginal gingiva, the supragingival plaque was removed. GCF was collected by placing the microcapillary pipette (Sigma-Aldrich, St. Louis, MO) at the entrance of the gingival sulcus (extrasulcular method) by gently touching the gingival margin. A standardized volume of $3 \mu \mathrm{L}$ was collected in single capillary from the same site, using the calibration on white color coded 1 to $5 \mu \mathrm{L}$ calibrated volumetric microcapillary pipettes. A maximum of ten minutes was given for each sample collection, and the sites that did not express any GCF within the allotted time were excluded. The micro-pipettes that were suspected to be contaminated with blood and saliva were excluded from the study. The collected GCF samples were transferred to airtight plastic vials and stored at $-70^{\circ} \mathrm{C}$ until assayed.

\section{Serum samples collection}

The skin over the antecubital fossa was disinfected and $2 \mathrm{~mL}$ of blood were collected by venipuncture using a 20-gauge needle with $2 \mathrm{~mL}$ syringes and were immediately transferred to the laboratory. The blood sample was allowed to clot at room temperature and after one hour it was centrifuged at $1000 \mathrm{rpm}$ for ten minutes to separate the serum component. The serum was extracted 
and stored at $-70^{\circ} \mathrm{C}$ until the time of the assay procedure.

The technician who performed the enzyme-linked immunosorbent assays (ELISA) was unaware of the study groups.

\section{OSM assay}

OSM levels in GCF and serum, obtained from study participants, were measured using Human OSM ELISA (KRISHJEN BioSystems, Mumbai, India) according to the manufacturer's instructions. All reagents were allowed to warm to room temperature for at least 30 minutes prior to opening. All steps were performed carefully as per the guideline protocol provided by the manufacture. The absorbance of each well is read on an ELISA reader using $450 \mathrm{~nm}$ as the primary wavelength. The concentrations of OSM in both the GCF and serum tested samples were estimated using the standard curve.

\section{Statistical analysis}

All data were analyzed using a software program (SPSS ${ }^{\circledR}$ version 10.5, SPSS Inc., Chicago, USA). A test for the validity of normality assumption using standardized range statistics was performed and it was found that the assumption was valid. Accordingly parametric tests were carried out for comparing the means of OSM concentration in different groups. A paired " $t$ " test was used to compare OSM concentrations in GCF and serum in groups III and IV. Pair-wise comparison using Scheff's test for GCF and serum OSM was carried out to explore which pair or pairs differed significantly at $1 \%$ level of significance. Pearson's correlation test was used to observe any correlation between the serum OSM concentration and clinical parameters.

\section{Results}

The mean OSM concentrations in GCF and serum were observed to be the highest in group III i.e. $726.65 \pm 283.56$ and $65.59 \pm 12.37 \mathrm{pg} \cdot \mathrm{mL}^{-1}$ respectively. The mean GCF OSM concentration in group I and group II was $66.15 \pm 28.10$ and $128.33 \pm 22.96 \mathrm{pg} \cdot \mathrm{mL}^{-1}$ respectively, while it was below the detectable limit of the kit in serum sample of group I and group II, thus approximately corresponds to $0.00 \mathrm{pg} \cdot \mathrm{mL}^{-1}$. In group IV GCF OSM level was $95.50 \pm 38.85 \mathrm{pg} \cdot \mathrm{mL}^{-1}$ and was $39.98 \pm 16.69 \mathrm{pg} \cdot \mathrm{mL}^{-1}$ in the serum. For group II the mean OSM concentration in GCF $\left(128.33 \pm 22.96 \mathrm{pg} \cdot \mathrm{mL}^{-1}\right)$ was found to fall in between the concentrations obtained in group I and group III (Table 1).

Table 1 Descriptive statistics of the study population (mean \pm SD [range])

\begin{tabular}{|c|c|c|c|c|c|c|}
\hline Study groups & Age / years & $\mathrm{GI}$ & $\begin{array}{l}\mathrm{CAL} \\
/ \mathrm{mm}\end{array}$ & $\begin{array}{l}\mathrm{PD} \\
/ \mathrm{mm}\end{array}$ & $\begin{array}{l}\text { GCF OSM concentration } \\
\qquad /\left(\mathrm{pg} \cdot \mathrm{mL}^{-1}\right)\end{array}$ & $\begin{array}{c}\text { Serum OSM concentration } \\
\qquad /\left(\mathrm{pg} \cdot \mathrm{mL}^{-1}\right)\end{array}$ \\
\hline Group I & $28.75 \pm 3.78$ & $0.00 \pm 0.00$ & $0.00 \pm 0.00$ & $1.90 \pm 0.72$ & $66.15 \pm 28.10$ & $0.00 \pm 0.00^{*}$ \\
\hline$(n=20)$ & $(25,39)$ & - & - & $(1,3)$ & $(35.0,103.5)$ & - \\
\hline Group II & $28.50 \pm 4.01$ & $1.92 \pm 0.52$ & $0.00 \pm 0.00$ & $2.65 \pm 0.49$ & $128.33 \pm 22.96$ & $0.00 \pm 0.00^{*}$ \\
\hline$(n=20)$ & $(25,42)$ & $(1.1,2.8)$ & - & $(2,3)$ & $(115.0,180.5)$ & - \\
\hline Group III & $30.60 \pm 6.24$ & $2.33 \pm 0.39$ & $5.05 \pm 1.67$ & $7.10 \pm 1.80$ & $762.65 \pm 283.56$ & $5.59 \pm 12.37$ \\
\hline$(n=20)$ & $(25,42)$ & $(1.4,2.8)$ & $(2,9)$ & $(5,11)$ & $(460.0,1115.0)$ & $(50.0,87.5)$ \\
\hline Group IV & $30.60 \pm 6.24$ & $0.37 \pm 0.48$ & $2.35 \pm 1.76$ & $4.15 \pm 2.60$ & $95.50 \pm 38.85$ & $39.98 \pm 16.69$ \\
\hline$(n=20)$ & $(25,42)$ & $(0,1.4)$ & $(2,4)$ & $(2,8)$ & $(50.0,170.0)$ & $\left(0.0^{*}, 68.5\right)$ \\
\hline
\end{tabular}

*OSM in serum of group I and group II patient was below the detectable limit of the ELISA kit (sensitivity $5.0 \mathrm{pg} \cdot \mathrm{mL}^{-1}$ ).

One way ANOVA analysis showed that differences in the levels of GCF OSM in group I and III, group II and III, and group III and IV were statistically significant at $P<0.01$ (Table 2). The differences in the levels of serum OSM in group I and III, group I and IV, group II and III, group II and IV, and group III and IV were found to be statistically significant at $P<0.01$ (Table 3 ). 
Pearson's Correlation coefficient test was used to observe the correlation between clinical parameters i.e. GI, PD, CAL and OSM concentration in GCF and serum. There is gradual increase in these clinical parameters from group I to group III and positively correlated with GCF OSM concentrations. Again, reduction in these clinical parameters after the treatment in group IV, showed a positive correlation with GCF OSM concentration (Table 4). For correlation between the clinical parameters and serum OSM concentration, Pearson's Correlation coefficient test was found to be positive for group III and group IV (Table 4). Reduction in GI, PPD and CAL again positively correlated with reduction in serum OSM concentration for group IV. There was a significant improvement in clinical parameters after the nonsurgical periodontal therapy (SRP) in patients in group III. This improvement in clinical parameters was also in accordance with significant reductions in the GCF and serum concentrations of OSM after SRP in patients with chronic periodontitis (Tables 3 and 4 ).

Table 2 Results of One way ANOVA comparing GCF OSM concentration in four groups and the pair-wise comparison using the Scheff's test for all four groups

\begin{tabular}{lccc}
\hline \multirow{2}{*}{ Study group } & GCF OSM & & \multicolumn{2}{c}{ Pair-wise comparison among the groups } \\
\cline { 2 - 4 } concentration / $\left(\mathrm{pg} \cdot \mathrm{mL}^{-1}\right)$ & Study groups & 0.6047 \\
Group I & $66.15 \pm 28.10$ & Group I and group II & $<0.001^{*}$ \\
Group II & $128.33 \pm 22.96$ & Group I and group III & 0.9370 \\
Group III & $726.65 \pm 283.56$ & Group I and group IV & $<0.001^{*}$ \\
Group IV & $95.50 \pm 38.85$ & Group II and group III & 0.9146 \\
F-value & 95.98 & Group II and group IV &
\end{tabular}

Table 3 One way ANOVA test results of comparing serum OSM concentration in four groups and the pair-wise comparison using the Scheff's test for all four groups

\begin{tabular}{cccc}
\hline \multirow{2}{*}{ Study group } & Serum OSM & \multicolumn{2}{c}{ Pair-wise comparison among the groups } \\
\hline concentration / $\left(\mathrm{pg} \cdot \mathrm{mL}^{-1}\right)$ & Study groups & $P$-value \\
\hline Group I & $0.00 \pm 0.00$ & Group I and group II & $<0.001^{*}$ \\
Group II & $0.00 \pm 0.00$ & Group I and group III & $<0.001^{*}$ \\
Group III & $65.59 \pm 12.37$ & Group I and group IV & $<0.001^{*}$ \\
Group IV & $39.98 \pm 16.69$ & Group II and group III & $<0.001^{*}$ \\
F-value & 192.3918 & Group II and group IV & $<0.001^{*}$ \\
P-value & $<0.001^{*}$ & Group III and group IV &
\end{tabular}

* Significant at $1 \%$ level of significance $(P<0.01)$.

Table 4 Pearson's correlation coefficient test comparing the GCF and serum OSM to GI, PD, and CAL clinical parameters among the groups

\begin{tabular}{|c|c|c|c|c|}
\hline & Study groups & $\mathrm{GI}$ & PD & CAL \\
\hline \multirow[t]{4}{*}{ GCF OSM } & Group I & - & $0.88^{*}$ & - \\
\hline & Group II & $0.90^{*}$ & $0.56^{*}$ & - \\
\hline & Group III & $0.51^{*}$ & $0.89^{*}$ & $0.75^{*}$ \\
\hline & Group IV & $0.92^{*}$ & $0.92^{*}$ & $0.80^{*}$ \\
\hline \multirow[t]{4}{*}{ Serum OSM } & Group I & - & - & - \\
\hline & Group II & - & - & - \\
\hline & Group III & 0.43 & $0.85^{*}$ & $0.79^{*}$ \\
\hline & Group IV & $0.61^{*}$ & $0.62^{*}$ & $0.68^{*}$ \\
\hline
\end{tabular}

*Significant at 0.05 level $(P<0.05)$ 
Table 5 Paired " $t$ " test to compare group III and group IV with all the variables

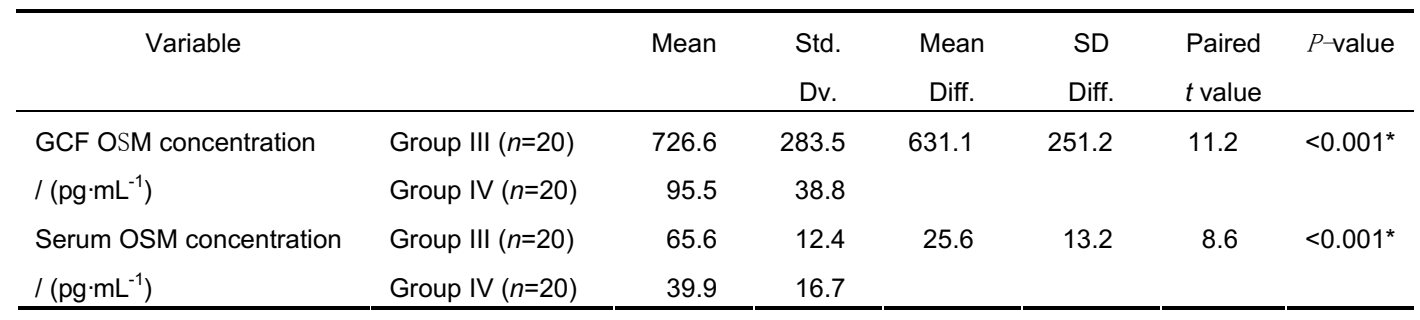

*Significant at 0.05 level $(P<0.05)$.

When group III and group IV were compared using paired " $t$ " test, the difference in the concentrations of OSM was statistically significant in both the GCF and serum suggesting that after scaling and root planing, OSM levels decreased considerably both in GCF (from $726.6 \mathrm{pg} \cdot \mathrm{mL}^{-1}$ to $95.5 \mathrm{pg} \cdot \mathrm{mL}^{-1}$ ) and proportionally in serum (from $65.6 \mathrm{pg} \cdot \mathrm{mL}^{-1}$ to $39.9 \mathrm{pg} \cdot \mathrm{mL}^{-1}$ ) (Table 5). Karl Pearson's Correlation coefficient test was performed to find any correlation between the GCF and serum OSM concentrations. The results showed a positive correlation in group III and group IV (Table 6).

Further, the concentration of OSM in GCF increases proportionally with the progression of the periodontal disease and decreased after SRP. Also, with an increase in the severity of periodontitis, an increased in the serum OSM level was noted and it decreased after SRP.

Table 6 Correlation between serum OSM versus GCF using Karl Pearson's correlation coefficient test

\begin{tabular}{cc}
\hline Study groups & Correlation coefficient \\
\hline Group I & - \\
Group II & - \\
Group III & $0.89^{*}$ \\
Group IV & $0.74^{*}$ \\
\hline
\end{tabular}

*Significant at 0.05 level $(P<0.05)$.

\section{Discussion}

The present clinico-biochemical study was designed to estimate the GCF and serum OSM levels in periodontal health and disease as well as evaluated any correlation between these levels. Having four groups in our study helped us to better evaluate the roles of OSM in the different stages of periodontal disease, from healthy to gingivitis to periodontitis; and, the effect of periodontal therapy on it. The variability of the concentrations in each group could be due to different stages of the disease process at the time of collection of the GCF samples. Sample collection in group IV was performed after 6-8 weeks because most of the inflammation has subsided and healing will generally occur by the six week mark; though, repair may continue for a long time (Badersten et al., 1981). GCF sample collection was performed using the microcapillary pipettes which were placed extrasulcular (not placed into the gingival sulcus) to the marginal gingiva to avoid trauma and contamination by attachment of the analyte, which is mostly seen with the use of filter paper (Griffiths, 2003). In the present study, the influence of age and gender of the subjects on the serum OSM concentration was minimized by including the equal number of males and female in each group and selecting the subjects within the specified age group of 25-50 years.

Presence of large number of cytokines, mainly proinflammatory and inflammatory cytokines, in the GCF have been proposed as potentially useful diagnostic or prognostic markers of periodontal destruction (Genco, 1998; Kamma et al., 2009). Therefore, in the present study we have evaluated the levels of OSM not only in GCF but also in the serum of gingivitis and chronic periodontitis patients and also evaluated the effect of the nonsurgical periodontal therapy (i.e. SRP) on it. It has been found that the GCF OSM level was increased proportionally with the severity and progression of the periodontal disease (raw data not shown). Again, it has been found that this increase was significantly reduced after the periodontal therapy (SRP) in GCF and serum, suggesting its role in the inflammation. This data is in accordance with the 
previous study by Lin et al. who showed the increased concentration in the GCF of mild, moderate and chronic periodontitis patients and was positively correlated with the IL-6 concentration in GCF (Lin et al., 2005). Apart from this we have evaluated the OSM levels in GCF of gingivitis patient which were not evaluated previously. To the best of our knowledge, the present study is the first to evaluate the OSM concentration in the serum of chronic periodontitis and GCF of gingivitis patients, and addressed its significant decrease after the nonsurgical periodontal therapy (SRP). It has been noted that OSM in the serum of healthy and gingivitis-suffering patients was below the detectable limit of the kit $\left(\approx 0.0 \mathrm{pg} \cdot \mathrm{mL}^{-1}\right)$ suggesting the difference in soft and hard tissue destruction of the periodontium, which explores its role in inflammation and bone resorption. Results of the present study are in accordance with the previous study by Naemura and Radka whofailed to detect OSM in plasma and serum of healthy subjects (Naemura and Radka, 1993). The significant increase in serum OSM concentration in chronic periodontitis patients can be attributed to a possible spillover from the diseased periodontal tissues.

A search for possible key cytokines involved in this process might clarify the mechanisms involved in the activation of the collagen breakdown and, consequently, the loss of attachment and bone destruction. The OSM may be one of the gp130 cytokine (IL-6, IL-11, and leukemia inhibitory factor) involved in the progression of the periodontal disease. In the cascade of periodontal inflammation, in response to bacterial products, human $\mathrm{T}$ cells and monocyte lineages can synthesize and secrete large amounts of OSM which may induce prolonged expression of P-selectin (Yao et al., 1996), E-selectin, intercellular adhesion molecule-1 (ICAM-1), and vascular cell adhesion molecule-1 (VCAM-1) which modulates leukocytes adhesion and recruits in large number to inflammatory sites (Modur et al., 1997), causing the destruction of periodontal tooth supporting structures.

Recently, studies have shown that periodontal resident cells (i.e. periodontal ligament fibroblasts or mesenchymal tissues) can also be induced to express the receptor activator of nuclear factor kappa- $\beta$ ligand (RANKL)/osteoprotegerin under microbial or microbial product induced inflammatory conditions in vivo or in vitro, suggesting the broad range and contributions of the cytokine RANKL/RANK/osteoprotegerin signaling network in periodontal disease (Belibasakis et al., 2007; Hasegawa et al., 2002; Wara-aswapati et al., 2007). OSM may cause bone resorption by acting on both osteoblasts and osteoclasts through autocrine IL-6 and paracrine RANKL regulation or it may act synergistically with IL-6 or TNF- $\alpha$ to, up-regulate the production of MMPs or augment IL-6 production (Lin et al., 2005; Sakai et al., 2006) and causes alveolar bone resorption in periodontitis.

Recent evidence suggests that periodontal infection may significantly enhance the risk for certain systemic diseases or alter the natural course of these conditions which include cardiovascular disease, diabetes mellitus, preterm birth, respiratory diseases, stroke etc. (Page and Beck, 1997; Mealey et al., 1999; Friedewald et al., 2009). Increased OSM concentration in serum or at tissue level have confirmed its role in the development of atherosclerosis (Modur et al., 1997), rheumatoid arthritis (Hui et al., 1997), multiple myeloma (Halin et al., 2000), and Kaposis sarcoma (Cai et al., 1994). Therefore such increase in the serum concentration in chronic periodontitis patients may exaggerate or provoke such conditions in otherwise healthy individuals. Also, decreased levels of cytokines after periodontal therapy may reduce the risk for such conditions. This is supported by studies that showed the positive effect of periodontal therapy on the decreased level of glycated hemoglobin $\left(\mathrm{HBA} 1_{\mathrm{C}}\right)$ in diabetes mellitus patients (Nagata, 2009) and the reduced risk of cardiovascular diseases (Blaizot et al., 2009).

The increase in serum levels of OSM can be attributed to possible spillover from the GCF or gingival tissues to peripheral circulation, or it could be due to a systemic inflammatory response to progressive disease in the periodontal pocket. Different inflammatory mediators (IL-6, TNF- $\alpha$, PGE 2) can induce OSM production and high serum levels of these molecules like acute phase proteins, C-reactive proteins, and IL-6 which have already been reported in periodontal disease (Ebersole et al., 1997; Loos et al., 2000). Thus, this increased OSM concentration in the serum of periodontitis patients may modulate chemokine and 
metalloproteinase production by synovial cells of the joint (Langdon et al., 1997) which may exaggerate or develop the rheumatoid arthritis. Also, increased serum OSM may cause development of atherosclerotic lesions by inducing endothelial cell P-selectin- and E-slectin-dependent PMN adhesion, CXC chemokine synthesis (Lin et al., 2005), vascular calcification through production of various inflammatory mediators (IL-6, TNF $\alpha$ ) (Shioi et al., 2006), and may increase the plasminogen activator inhibitor-1 which leads thrombogenicity of vessels (Pourtau et al., 1998).

However, further longitudinal studies involving larger populations are needed to confirm these findings and to better understand the role of OSM cytokines in the pathogenesis of periodontal diseases and its role in above-mentioned systemic diseases.

\section{Conclusion}

Based on the findings of the present study, increased OSM levels in both the GCF and serum may suggest its role in the pathogenesis of periodontal disease. Again, such an increase in serum concentration may exaggerate the other systemic conditions and effective periodontal therapy may prevent such complications. Further, longitudinal prospective studies are needed to affirm the findings of the present study.

\section{Acknowledgements}

The present study was partly funded by Colgate Research Grant, Colgate-Palmolive India Ltd., Mumbai, India.

Authors thank Colgate-Palmolive India Ltd., Mumbai, India; for partly funding this research project. Authors report no conflicts of interest related to this study.

\section{References}

Badersten A, Nilveus R, Egelberg J (1981). Effect of nonsurgical periodontal therapy. I. Moderately advanced periodontitis. J Clin Periodontol, 8(1): 57-72.

Belibasakis GN, Bostanci N, Hashim A, Johnsson A,
Aduse-Opoku J, Curtis MA, et al. (2007). Regulation of RANKL and OPG gene expression in human gingival fibroblasts andperidoontal lignament cells by Porphyromonas gingivalis: a putative role of the Arggingipains. Microb Pathog, 43(1): 46-53.

Birkedal-Hansen H (1993). Role of cytokines and inflammatory mediators in tissue destruction. $J$ Periodontal Res, 28(6 Pt 2): 500-510.

Blach A, Franek E, Witula A, Kolonko A, Chudek J, Drugacz J, et al. (2009). The influence of chronic periodontitis on serum TNF-alpha, IL-6 and hs-CRP concentrations, and function of graft and survival of kidney transplant recipients. Clin Transplant, 23(2): 213-219.

Blaizot A, Vergnes JN, Nuwwareh S, Amar J, Sixou M (2009). Periodontal diseases and cardiovascular events: meta-analysis of observational studies. Int Dent $J$, 59(4): 197-209.

Bostanci N, Ilgenli T, Emingil G, Afacan B, Han B, Töz H, et al. (2007). Gingival crevicular fluid levels of RANKL and OPG in periodontal diseases: implications of their relative ratio. J Clin Periodontol, 34(5): 370376.

Bostanci N, Ilgenli T, Emingil G, Afacan B, Han B, Töz H, et al. (2007). Differential expression of receptor activator of nuclear factor-kappaB ligand and osteoprotegerin mRNA in periodontal diseases. $J$ Periodontal Res, 42(4): 287-293.

BrownTJ, Rowe JM, Liu JW, Shoyab M (1991). Regulation of IL-6 expression by Oncostatin M. $J$ Immunol, 147(7): 2175-2180.

Bruce AG, Hoggatt IH, Rose TM (1992). Oncostatin M is a differentiation factor for myeloid leukemia cells. $J$ Immunol, 149(4): 1271-1275.

Cai J, Gill PS, Masood R, Chandrasoma P, Jung B, Law $\mathrm{RE}$, et al. (1994). Oncostatin-M is an autocrine growth factor in Kaposi's sarcoma. Am J Pathol, 145(1): 74 -79 .

Dağ A, Firat ET, Arikan S, Kadiroğlu AK, Kaplan A (2009). The effect of periodontal therapy on serum TNF-alpha and HbAlc levels in type 2 diabetic patients. Aust Dent J, 54(1): 17-22.

Ebersole JL, Machen RL, Steffen MJ, Willmann DE (1997). Systemic acute-phase reactants, C-reactive protein and haptoglobin, in adult periodontitis. Clin Exp Immunol, 107(2): 347-352.

Friedewald VE, Kornman KS, Beck JD, Genco R, Goldfine A, Libby P, et al. (2009). The American Journal of Cardiology and Journal of Periodontology 
Editors' Consensus: periodontitis and atherosclerotic cardiovascular disease. Am J Cardiol, 104(1): 59-68.

Fujihashi K, Kono Y, Beagley KW, Yamamoto M, McGhee JR, Mestecky J, et al. (1993). Cytokines and periodontal disease: immunopathological role of interleukins for B cell responses in chronic inflamed gingival tissues. J Periodontol, 64(5 Suppl): 400-406.

Genco RJ (1992). Host responses in periodontal diseases: current concepts. J Periodontol, 63(4 Suppl): 338-355.

Griffiths GS (2003). Formation, collection and significance of gingival crevicular fluid. Periodontol 2000, 31: 3242.

Goren I, Kampfer H, Müller E, Schiefelbein D, Pfeilschifter J, Frank S (2006). Oncostatin M expression is functionally connected to neutrophils in the early inflammatory phase of skin repair: implications for normal and diabetes-impaired wounds. J Invest Dermatol, 126(3): 628-637.

Urbańska-Ryś H, Wiersbowska A, Stepień H, Robak T (2000). Relationship between circulating interleukin-10 (IL-10) with interleukin-6 (IL-6) type cytokines (IL-6, interleukin-11 (IL-11), oncostatin M (OSM)) and soluble interleukin-6 (IL-6) receptor (sIL-6R) in patients with multiple myeloma. Eur Cytokine Netw, 11(3): 443-451.

Hasegawa T, Yoshimura Y, Kikuiri T, Yawaka Y, Takeyama S, Matsumoto A, et al. (2002). Expression of receptor activator of NF-kappa B ligand and osteoprotegerin in culture of human periodontal ligament cells. J Periodontal Res, 37(6): 405-411.

Hui W, Bell M, Carroll G (1997). Dection of oncostatin M in synovial fluid from patients with rheumatoid arthritis. Ann Rheum Dis, 56: 184-187.

Hussain Bokhari SA, Khan AA, Tatakis DN, Azhar M, Hanif M, Izhar M (2009). Non-surgical periodontal therapy lowers serum inflammatory markers: a pilot study. J Periodontol, 80(10): 1574-1580.

Jotwani R, Cutler CW (1998). Adult periodontitis-specific bacteria infection or chronic inflammation? J Med Microbiol, 47(3): 187-188.

Kamma J, Mombelli A, Tsinidou K, Vasdekis V, Giannopoulou C (2009). Cytokines in gingival crevicular fluid of adolescents and young adults. Oral Microbiol Immunol, 24(1): 7-10.

Lang NP, Bartold PM, Cullinam M, Jeffcoat M, Mombelli A, Murakami S, et al. (1999). International classification workshop. Consensus report: Aggressive periodontitis. Ann Periodontol, 4: 53.

Langdon C, Leith J, Smith F, Richards CD (1997).
Oncostatin M stimulates monocyte chemoattractant protein-1 and interleukin-1 induced matrix metalloproteinase-1 production by human synovial fibroblasts in vitro. Arthritis Rheum, 40(12): 2139-2146.

Lin SJ, Chen YL, Kuo MY, Li CL, Lu HK (2005). Measurement of gp130 cytokine oncostatin $\mathrm{M}$ and IL-6 in gingival cervicular fluid of patients with chronic periodontitis. Cytokine, 30(4): 160-167.

Listgarten MA (1986). Pathogenesis of periodontitis. J Clin Periodontal, 13(5):418-430.

Loe H, Silness J (1963). Perioontal disease in pregnancy. I: prevalence and severity. Acta Odontol Scand, 21: 533.

Loos BG, Craandijk J, Hoek FJ, Wertheim-van Dillen PM, van der Velden V (2000). Elevation of systemic markers related to cardiovascular diseases in the peripheral blood of periodontitis patients. J Periodontol, 71(10): 1528-1534.

Lu HK, Chen YL, Chang HC, Li CL, Kuo MY (2006). Identification of the osteoprotegerin/receptor activator of nuclear factor kappa B ligand system in gingival crevicular fluid and tissue of patients with chronic periodontitis. J Periodontal Res, 41(4): 354-360.

Manicourt DH, Poilvache P, van Egeren A, Devogelaer JP, Lenz ME, Thonar EJ (2000). Synovial fluid levels of tumor necrosis factor alpha and oncostatin M correlate with levels of markers of the degradation of crosslinked collagen and cartilage aggrecan in rheumatoid arthritis but not in osteoarthritis. Arthritis Rheum, 43(2): 281- 288.

Mealey BL (1999). Influence of periodontal infections on systemic health. Periodontol 2000, 21: 197-209.

Modur V, Feldhaus MJ, Weyrich AS, Jicha DL, Prescott SM, Zimmerman GA, et al. (1997). Oncostatin M is a proinflammatory mediator. In vivo effects correlate with endothelial cell expression of inflammatory cytokines and adhesion molecules. J Clin Invest, 100(1): $158-168$.

Naemura JR, Radka SF (1993). Detection of oncostatin M in human plasma and serum by a sensitive enzyme immunoassay. Lymphokine Cytokine Res, 12(3): 187190.

Nagata T (2009). Relationship between diabetes and periodontal disease. Clin Calcium, 19(9): 1291-1298.

Okada H, Murakami S (1998). Cytokine expression in periodontal health and disease. Crit Rev Oral Biol Med, 9(3): 248-266.

Page RC, Beck JD (1997). Risk assessment for periodontal diseases. Int Dent J, 47(2): 61-87.

Pourtau J, Soria C, Paysant J, Vannier JP, Vasse M (1998). 
In vitro effect of oncostatin $\mathrm{M}$ on the release by endothelial cells of von Willebrand factor, tissue type plasminogen activatorand plasminogen activator inhibitor-1. Blood Coagul Fibrinolysis, 9(7): 609-615.

Sakai A, Ohshima M, Sugano N, Otsuka K, Ito K (2006). Profiling the cytokines in gingival crevicular fluid using a cytokine antibody array. $J$ Periodontol, 77(5): 856- 864 .

Shapira L, van Dyke TE, Hart TC (1992). A localized absence of IL-4 triggers periodontal disease activity: a novel hypothesis. Med Hypotheses, 39(4): 319-322.

Shioi A, Katagi M, Okuno Y, Mori K, Jono S, Koyama H, et al. (2002). Induction of bone-type alkaline Phosphatase in human vascular smooth muscle cells roles of tumor necrosis factor- $\alpha$ and oncostatin $\mathrm{M}$ derived from macrophages. Circ Res, 91(1): 9-16.

Stashenko P, Fujiyoshi P, Obernesser MS, Prostak L, Haffajee AD, Socransky SS (1991). Levels of interleukin 1 in tissue from sites of active periodontal disease. J Clin Periodontol, 18(7): 548-554.

Suda T, Chida K, Todate A, Ide K, Asada K, Nakamura Y, et al. (2002). Oncostatin M production by human dendritic cells in response to bacterial products. Cytokine, 17(6): 335-340.
Talbert J, Elter J, Jared HL, Offenbacher S, Southerland J, Wilder RS (2006). The effect of periodontal therapy on TNF-alpha, IL-6 and metabolic control in type 2 diabetics. J Dent Hyg, 80(2): 7.

Tanaka M, Miyajima A (2003). Oncostatin M, a multifunctional cytokine. Rev Physiol Biochem Pharmacol, 149: 39-52.

Vernal R, Chaparro A, Graumann R, Puente J, Valenzuela MA, Gomonal J (2004). Levels of cytokine receptor activator of nuclear factor kappaB ligand in gingival crevicular fluid in untreated chronic periodontitis patients. J Periodontol, 75(12): 1586-1591.

Wara-aswapati N, Surarit R, Chayasadom A, Boch JA, Pitiphat W (2007). RANKL upregulation associated with periodontitis and Porphyromonas gingivalis. $J$ Periodontol, 78(6): 1062-1069.

Yao L, Pan J, Setiadi H, Patel KD, McEver RP (1996). Interleukin 4 or oncostatin $\mathrm{M}$ induces a prolonged increase in P-selectin mRNA and protein in human endothelial cells. $J$ Exp Med, 184(1): 81-92.

Yun F, Firkova EI, Xun H, Jun-Qi L (2007). Effects of surgical periodontal therapy on serum levels of TNF-alpha in patients with chronic periodontitis. Folia Med (Plovdiv), 49(1/2): 37-40.

*Corresponding author: ManojKumar Thorat

Address: Department of Periodontics, Government Dental College and Research Institute, Fort, Bangalore-560002, Karnataka, India.

Tel: $919986495941 \quad$ E-mail: manojthoratmds@rediffmail.com 